\title{
Loss of GPER identifies new targets for therapy among a subgroup of $E R \alpha$-positive endometrial cancer patients with poor outcome
}

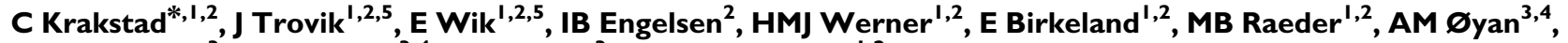 \\ IM Stefansson ${ }^{3}$, KH Kalland ${ }^{3,4}$, LA Akslen ${ }^{3}$ and HB Salvesen ${ }^{1,2}$ \\ 'Department of Clinical Medicine, Section for Gynecology and Obstetrics, University of Bergen, Jonas Lies Vei 72, Bergen 5020, Norway; ${ }^{2}$ Department of \\ Gynecology and Obstetrics, Haukeland University Hospital, Haukeland, Norway; ${ }^{3}$ The Gade Institute, University of Bergen, Bergen, Norway; ${ }^{4}$ Department \\ of Microbiology, Haukeland University Hospital, Haukeland, Norway
}

BACKGROUND: The G protein-coupled oestrogen receptor, GPER, has been suggested as an alternative oestrogen receptor. Our purpose was to investigate the potential of GPER as a prognostic and predictive marker in endometrial carcinoma and to search for new drug candidates to improve treatment of aggressive disease.

MATERIALS AND METHODS: A total of 767 primary endometrial carcinomas derived from three patient series, including an external dataset, were studied for protein and mRNA expression levels to investigate and validate if GPER loss identifies poor prognosis and new targets for therapy in endometrial carcinoma. Gene expression levels, according to ER $\alpha / G P E R$ status, were used to search the connectivity map database for small molecular inhibitors with potential for treatment of metastatic disease for receptor status subgroups.

RESULTS: LOSS of GPER protein is significantly correlated with low GPER mRNA, high FIGO stage, non-endometrioid histology, high grade, aneuploidy and ER $\alpha$ loss (all P-values $\leqslant 0.05$ ). Loss of GPER among ER $\alpha$-positive patients identifies a subgroup with poor prognosis that until now has been unrecognised, with reduced 5 -year survival from $93 \%$ to $76 \%(P=0.003)$. Additional loss of GPER from primary to metastatic lesion counterparts further supports that loss of GPER is associated with disease progression.

CONCLUSION: These results support that GPER status adds clinically relevant information to ER $\alpha$ status in endometrial carcinoma and suggest a potential for new inhibitors in the treatment of metastatic endometrial cancers with ER $\alpha$ expression and GPER loss. British Journal of Cancer (2012) I 06, 1682- 1688. doi: I0.1038/bjc.2012.91 www.bjcancer.com

Published online 13 March 2012

(c) 2012 Cancer Research UK

Keywords: endometrial cancer; GPER; ER $\alpha$; HDAC-inhibitor

In industrialised countries, endometrial cancer is the most common pelvic gynaecologic malignancy, with a $2-3 \%$ lifetime risk. Hormone receptor status in patients with endometrial cancer is an established prognostic marker (Engelsen et al, 2008), where loss of hormone receptors $\mathrm{ER} \alpha$ or PR predicts poor survival. Oestrogen receptor $\alpha$ and PR statuses have also been reported to predict response to anti-hormonal therapy in metastatic endometrial cancer (Singh et al, 2007). Still, in contrast to breast cancer treatment, hormone receptor status has not yet routinely been implemented in the clinics to improve and individualise endometrial cancer therapy. Thus, a more systematic approach to tailored treatment based on receptor status is needed in endometrial cancer.

The discovery of the $G$ protein-coupled receptor GPER (formerly GPR30) as an alternative oestrogen receptor (Carmeci et al, 1997; Filardo et al, 2000) has added complexity to this task. GPER is a seven-transmembrane receptor that binds $17 \beta$-estradiol but differs from the classic oestrogen receptors (ER $\alpha$ and $\operatorname{ER} \beta)$ by

\footnotetext{
*Correspondence: Dr C Krakstad; E-mail: camilla.krakstad@med.uib.no
} ${ }^{5}$ These authors contributed equally to this work.

Received 12 January 2012; revised 17 February 2012; accepted 23 February 2012; published online 13 March 2012 eliciting nongenomic, rapid signalling as well as genomic transcriptional events of oestrogen. The GPER has been ascribed roles in the immune, cardiovascular, endocrine and reproductive system, and dysregulation of its expression has also been reported in cancer (Maggiolini and Picard, 2010; Prossnitz and Barton, 2011).

The ER modulator tamoxifen and the ER inhibitor fulvestrant are used in the treatment of metastatic endometrial cancer, with modest response rates (Decruze and Green, 2007). Interestingly, these ER modulators also act as GPER agonists (Filardo et al, 2000, 2002; Thomas et al, 2005) and the risk of unwanted side effects from treatment is present. This highlights the need for improved definition of drug targets and molecular subgroups in addition to the ER status. Such knowledge will be particularly important to promote biomarker restricted phase I/II trials.

In the present study we hypothesised that GPER loss defines an aggressive subgroup among ER $\alpha$-positive patients with molecular alterations reflected in distinct transcriptional signatures, indicating new targets for therapy. We report for the first time to the best of our knowledge, a link between GPER loss and poor prognosis in ER $\alpha$-positive endometrial carcinomas. Also, drugs targeting HDACs are identified through a search in the small molecule database Connectivity Map as promising to treat metastatic disease in $\mathrm{ER} \alpha$-positive tumours with GPER loss. 


\section{MATERIALS AND METHODS}

\section{Patient series and tumour specimens}

We have studied a total of 767 endometrial cancer patients from three independent patient series with primary tumour tissue available. Two population based patient series with formalin-fixed paraffin-embedded tissue (FFPE) from primary tumours were used for immunohistochemical staining as primary investigation $(n=182)$ and prospective validation series $(n=474)$. For patients with advanced or recurrent disease in the prospective series, FFPE biopsies were collected from metastatic tissue in parallel when available, and mounted in tissue microarrays (TMAs; $n=78$ ). From the prospective validation set, two series with freshly frozen primary tumour tissue were used for mRNA studies, including a microarray set $(n=76)$ and one series used for validation of candidate genes by qPCR $(n=161)$. Freshly frozen tissue was collected in parallel with FFPE. One publicly available external microarray validation set was also investigated $(n=111)$.

For the two independent population-based patient cohorts with FFPE tissue available, tissues were mounted in TMA). These patients were diagnosed with endometrial carcinoma in Hordaland County (Norway) during the periods 1981-1990 (primary investigation set) and 2001-2009 (prospective validation set). For patients in the primary investigation set, tumour tissue was retrospectively collected and patients were staged according to FIGO 1988 criteria, whereas tumour tissue from patients in the prospective validation series was included prospectively and staged according to FIGO 2009 criteria. Tissue microarrays were generated as previously described and validated in several studies (Stefansson et al, 2004). Briefly, the area of highest tumour grade was identified on H\&E-stained slides, and three tissue cylinders were punched out from the selected areas of the donor block and mounted into a recipient paraffin block using a custom-made precision instrument (Beecher Instruments, Silver Spring, MD, USA). The majority of the selected samples were verified by frozen sections to contain $>80 \%$ malignant epithelial component (minimum purity $50 \%$ ). Age at diagnosis, FIGO stage, histological subtype and grade, treatment and follow-up were registered as previously reported (Salvesen et al, 1999; Trovik et al, 2011).

A publicly available endometrial carcinoma gene expression data set was obtained from the Expression Project for Oncology (expO: http://www.intgen.org/expo/). Clinico-pathologic data as well as GEO accession numbers for these 111 tumours have been described (Salvesen et al, 2009). The GEO data sets were run at Affymetrix U133 +2 arrays (Santa Clara, CA, USA). To construct transcript level probe sets, individual probes were sequence-matched against Aceview (NCB135) (Carter et al, 2006; Salvesen et al, 2009).

\section{Immunohistochemistry}

Tissue microarrays sections $(5 \mu \mathrm{m})$ were dewaxed with xylene, rehydrated in ethanol before microwave antigen retrieval, and stained for GPER expression using ab12564 and ab12563 (Abcam, Cambridge, UK) and for ER $\alpha$ expression using anti-ER $\alpha$ M7047 (Dako, Copenhagen, Denmark). The stainings were recorded as previously described (Salvesen et al, 2000; Engelsen et al, 2008). Briefly, a semiquantitative and subjective grading was used, and a staining index was calculated as a product of staining intensity $(0-3)$ and area of positive tumour cells $(1 \leqslant 10 \%, 2=10-50 \%$ and $3 \geqslant 50 \%$ ). Evaluation of the staining was carried out blinded for patient characteristics and outcome. In subsequent statistical analyses, staining index was categorised in quartiles considering the frequency distribution for each marker, the size of the subgroups and the number of events in each category. Groups with similar survival were merged. To estimate reproducibility of this scoring, two independent observers scored random TMA slides (95 patients for $\mathrm{ER} \alpha$ and 81 for GPER) and inter-observer
Kappa values were calculated to be 0.82 for $\mathrm{ER} \alpha$ and 0.80 for GPER. For patients with multiple metastases available, expression level was defined by any metastatic lesion demonstrating the loss of expression for ER $\alpha$ and/or GPER in cases of heterogeneity.

\section{Real-time quantitative PCR assays}

cDNA was synthesised from $1 \mu \mathrm{g}$ RNA by the High capacity RNA to cDNA kit (Applied Biosystems, Carlsbad, CA, USA). Gene expression of GPER was determined using the two equally good TaqMan gene expression assays GPER-Hs00173506_m1 (data not shown) and GPER-Hs01922715_s1 (Applied Biosystems), and all samples were run on microfluidic cards with GAPDHHs99999905_m1 as endogenous control. Assays were chosen using the UMapIt Microarray-to-TaqMan Assays Mapping Tool to ensure that the selected assays corresponded to the Agilent probes for microarray. Microfluidic cards were run as previously reported (Salvesen et al, 2009) and as described by the manufacturer. All samples were run in triplicates and analysed in RQ manager (Applied Biosystem software), using the $\mathrm{DDC}_{\mathrm{t}}$-based method for calculation of relative quantification (RQ) values (Livak and Schmittgen, 2001). Outliers and runs with standard deviation $>0.5$ among triplicates were excluded before analysis.

\section{Oligonucleotide DNA microarray analyses}

RNA was extracted using the RNeasy Mini Kit (Qiagen, Hilden, Germany) and hybridised to Agilent Whole Human Genome Microarrays 44k (Cat.no. G4112F), according to the manufacturer's instructions. Arrays were scanned using the Agilent Microarray Scanner Bundle. Raw data were imported and analysed in J-Express software (Molmine, Bergen, Norway). Mean spot signal was used as intensity measure, and expression data were normalised using median over entire array. Connectivity Map (http:// www.broadinstitute.org/cmap/) queries were performed independently for our microarray data and the external dataset using differentially expressed genes. Differentially expressed genes for $\mathrm{ER} \alpha$ expressing tumours according to GPER status $(\mathrm{ER} \alpha+1$ GPER $+v s \mathrm{ER} \alpha+/ \mathrm{GPER}-)$ were identified using the Feature subset selection (FSS) method $(P<0.05$, fold $>1.5)$ from 59 (internal set) and 58 (external set) $\mathrm{ER} \alpha+$ patients. The presented Connectivity Map results represent the top-ranked instances of the same perturbagen made in the given cell line (Lamb et al, 2006).

\section{Statistical analysis}

Statistical analyses were performed using PASW statistics 18.0 software for Mac (IBM, Armonk, NY, USA). Probability of $<0.05$ was considered statistically significant. Groups were compared using Pearson chi-square test or Fisher's exact test, when appropriate, for categorical variables. Mann - Whitney $U$ test and linear regression were used to test correlations for continuous variables. Univariate survival analyses of time to recurrence (recurrence free survival) or death due to endometrial carcinoma (disease specific survival) were performed using the Kaplan-Meier (product-limit) method. Entry date was the date of primary surgery. Patients who died from other causes were censored at the date of death. Differences in survival between groups were estimated by the log-rank (Mantel Cox) test. Variables were visually examined by a log-minus-log plot to check the assumptions about proportionality over time for inclusion in the multivariate proportional hazards regression models (Cox analyses). Unadjusted and adjusted hazard ratios were calculated as measures of effect. Significance of change in protein expression from primary tumours to corresponding metastatic lesions was evaluated using Fisher's exact and Wilcoxon signed rank tests. All $P$-values were two-sided. 


\section{RESULTS}

\section{Low GPER expression identifies aggressive endometrial cancers}

The GPER protein expression was seen both in the stroma and in the glandular tissue. Only staining in glandular tissue was scored systematically, and protein expression was mainly cytoplasmic (Figure 1C). Loss of GPER expression, as defined by the lower quartile, was highly significantly associated with reduced diseasespecific survival in the primary investigation set $(n=182$, Figure 1A). To further investigate the clinical phenotype related to GPER expression, we examined the larger prospectively collected validation series of 474 endometrial carcinoma patients. Low expression of GPER was significantly associated with high age, high FIGO stage, non-endometrioid histology, high grade, presence of lymph node metastasis, aneuploidy, ER $\alpha$ loss and poor prognosis (Figure 1B, Table 1) confirming the link between GPER loss and aggressive phenotype. In addition, proliferation activity was significantly higher in GPER-negative compared with positive tumours measured by mitotic count (median 17 compared with 10 , respectively, $P=0.006$, Mann-Withney $U$ test). The poor survival associated with GPER loss was also seen for the subgroup of endometrioid tumours only $(n=391)$, with an $80 \% 5$-year survival compared with $94 \%$ for tumours expressing GPER $(P=0.001$, Supplementary Figure $1 \mathrm{~A})$. When including GPER and $\mathrm{ER} \alpha$ in multivariate Cox regression analysis, GPER and $\mathrm{ER} \alpha$ were both found to be independent predictors of poor survival with hazard ratios (HR) of 1.9 for GPER $(P=0.03,95 \% \mathrm{CI}$ : $1.1-3.3)$ and 3.1 for $\operatorname{ER} \alpha(P<0.001,95 \%$ CI: $1.8-5.4)$.

To explore to what extent the protein level was reflected in mRNA expression, GPER gene expression data were investigated in 76 tumour specimens analysed by microarray and validated by qPCR in 161 patients independent from the microarray series. Low GPER mRNA expression was confirmed to predict poor diseasespecific survival (Figures $2 \mathrm{~A}$ and $\mathrm{C}$ ) and was significantly associated with the loss of GPER protein expression (Figures 2B and D). In both data sets, mRNA levels for GPER and ESR1 were significantly correlated $(P<0.001$, Pearson $r(s) 0.3$ and 0.6$)$. Low GPER mRNA expression also correlated with grade 3 in all examined mRNA datasets (Supplementary Table 1).

\section{Loss of GPER among ER $\alpha$-positive patients identifies poor prognosis}

As GPER is suggested as an alternative oestrogen receptor, we further investigated a possible link between expression levels of GPER and ERs in the larger prospective validation series. As expected, loss of $E R \alpha$ was consistently associated with markers for poor prognosis (Supplementary Table 2 ) as well as poor survival $(P<0.001$; Figure 3A). ER $\alpha$ loss also predicted poor survival in the subgroup of endometrioid tumours only $(P=0.001$, Supplementary Figure 1B). ER $\beta$ mRNA levels by microarray and qPCR were neither correlated with phenotype nor $\mathrm{ER} \alpha$ expression in tumour (data not shown). When combining the $\mathrm{ER} \alpha$ and GPER protein expression data, we find that GPER loss within the ER $\alpha$-positive subgroup of tumours significantly correlates with high FIGO stage, lymph node metastasis, non-endometrioid histology, high grade and aneuploidy (Table 2). Interestingly, combining the data also improved the prediction of outcome: ER $\alpha /$ GPER double positive was the most favourable group, whereas ER $\alpha / G P E R$ double

Table I GPER protein expression in prospectively collected tumours related to clinico-pathologic factors in 474 patients with endometrial carcinoma

\begin{tabular}{|c|c|c|c|}
\hline \multirow[b]{2}{*}{ Variable } & \multicolumn{2}{|c|}{ GPER $^{\mathbf{a}}$} & \multirow[b]{2}{*}{$P$-value } \\
\hline & High, $n$ (\%) & Low, $n$ (\%) & \\
\hline Age (years) & & & 0.05 \\
\hline$<66$ & $187(74)$ & $65(26)$ & \\
\hline$\geqslant 66$ & $146(66)$ & $76(34)$ & \\
\hline FIGO-09 stage & & & $<0.001$ \\
\hline I-II & $295(74)$ & $103(26)$ & \\
\hline III-IV & $38(50)$ & $38(50)$ & \\
\hline Histologic type & & & $<0.001$ \\
\hline Endometrioid & $302(77)$ & $89(23)$ & \\
\hline Non-endometrioid & 31 (37) & $52(63)$ & \\
\hline Histologic grade & & & $<0.001$ \\
\hline Grade I/2 & $265(81)$ & $62(19)$ & \\
\hline Grade 3 & $68(46)$ & $79(54)$ & \\
\hline Metastatic nodes & & & $<0.001$ \\
\hline Negative & $250(73)$ & $95(27)$ & \\
\hline Positive & $21(48)$ & $23(52)$ & \\
\hline Ploidy & & & $<0.001$ \\
\hline Diploid & 191 (74) & $66(26)$ & \\
\hline Aneuploid & $31(48)$ & $33(5 \mathrm{I})$ & \\
\hline$E R \alpha$ & & & $<0.001$ \\
\hline Positive & $292(80)$ & 7| (20) & \\
\hline Negative & 41 (37) & $70(63)$ & \\
\hline
\end{tabular}

Abbreviations: $E R \alpha=$ oestrogen receptor $\alpha$; GPER $=G$ protein-coupled oestrogen receptor. ${ }^{a}$ Low $=$ index $0-3$ (lowest quartile), high $=$ index $4-9$.
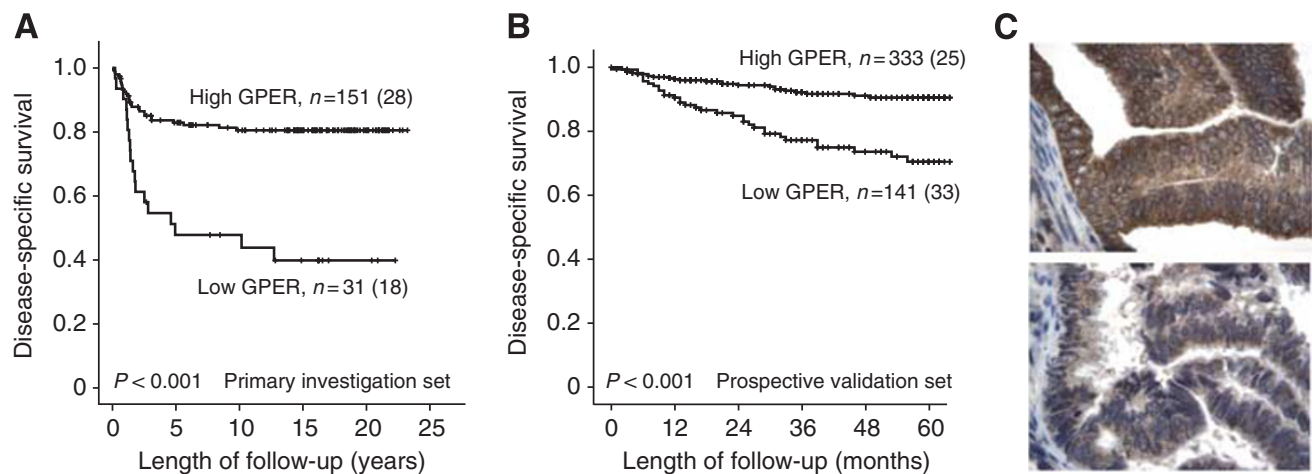

Figure I Loss of GPER expression in tumour is significantly associated with reduced survival for endometrial carcinomas. Kaplan-Meier curves for disease specific survival by expression of GPER protein in $(\mathbf{A})$ a primary investigation set $(n=182)$, and $(\mathbf{B})$ a prospectively collected validation series $(n=474)$. Representative examples of GPER expression (C); high expression in the upper panel compared with low cytoplasmic expression in the lower panel. 

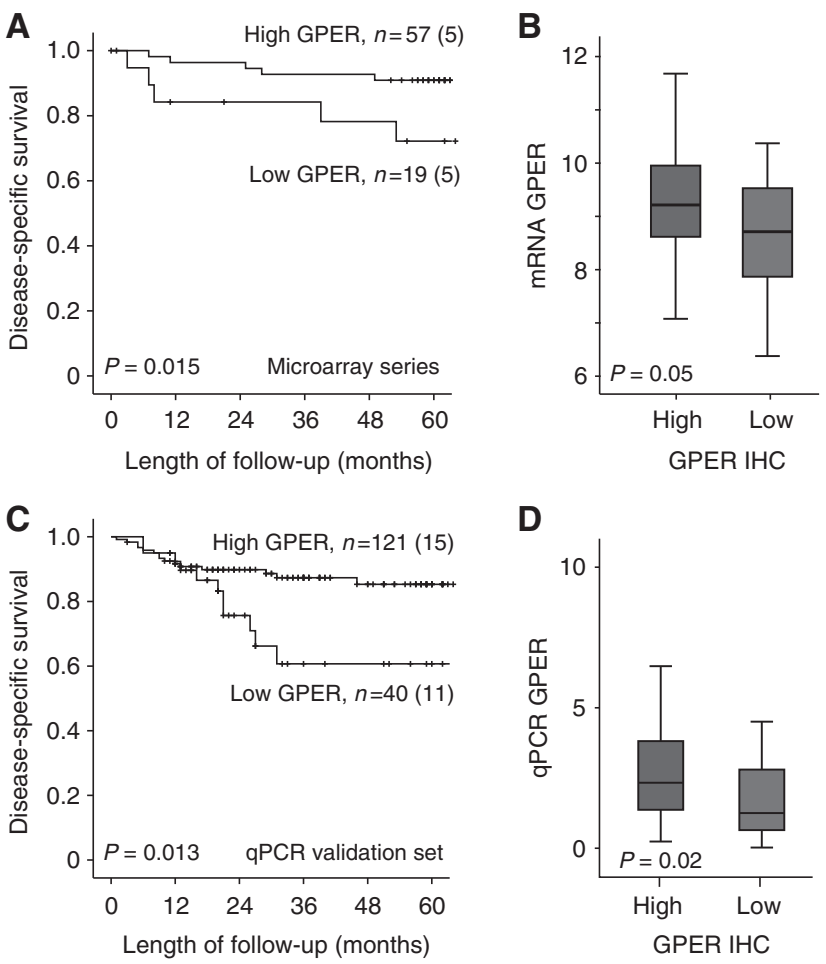

Figure 2 Low mRNA GPER expression predicted poor disease-specific survival (A) and was significantly correlated with low GPER protein expression (B) in the microarray series $(n=76)$. qPCR analysis of GPER mRNA expression in a series independent from the microarray set $(n=|6|)$ validated the poor outcome associated with low GPER mRNA (C) and significantly correlated with low GPER protein expression (D). Vertical bars on the survival curves represent censored cases.

negative was most unfavourable $(P<0.001$, Figure $3 \mathrm{~B})$. Among the ER $\alpha$-positive patients, normal GPER expression was associated with a $17 \%$ higher 5 -year disease-specific survival compared with patients with loss of GPER $(P=0.01$; Figure 3B). As intact expression of $\mathrm{ER} \alpha$ is regarded to be one of the hallmarks of endometrioid histology, we also investigated ER $\alpha /$ GPER expression for this subgroup, confirming the loss of GPER as a factor predicting poor prognosis for endometrioid tumours $(P=0.002$, Figure 3C). Cox multivariate analysis of patients with tumour confined to the uterus, endometrioid histology and intact expression of $\mathrm{ER} \alpha$ showed an independent prognostic impact of GPER with a HR of 7.3 (95\% CI: $1.8-29.6, P=0.006)$ adjusted for age and grade.

\section{Loss of GPER from primary to metastatic lesions is common for $\mathrm{ER} \alpha$ expressing primary tumours}

Consistent with the pattern of poor survival for patients with receptor loss, we find a significantly higher proportion of metastatic lesions compared with primary lesions, with loss of $\mathrm{ER} \alpha$ and GPER (Figures 4A and B). To evaluate to what extent the metastatic lesions showed receptor loss not present in the primary lesions, we further analysed the ER $\alpha / G P E R$ status in metastatic lesions from ER $\alpha$-positive primary tumours $(n=34)$. For ER $\alpha /$ GPER-positive primary tumours, $91 \%$ of the metastases lost at least one receptor and $61 \%$ lost both receptors compared with their primary lesion counterparts (Figure 4C, $P<0.001$, Wilcoxon signed rank test). In the $\mathrm{ER} \alpha+/ \mathrm{GPER}-$ subgroup of primary tumours, $45 \%$ of the metastases developed loss of ER $\alpha$ not present in the primary lesions (Figure $4 \mathrm{D}$, Wilcoxon signed Rank test; $P<0.03)$.
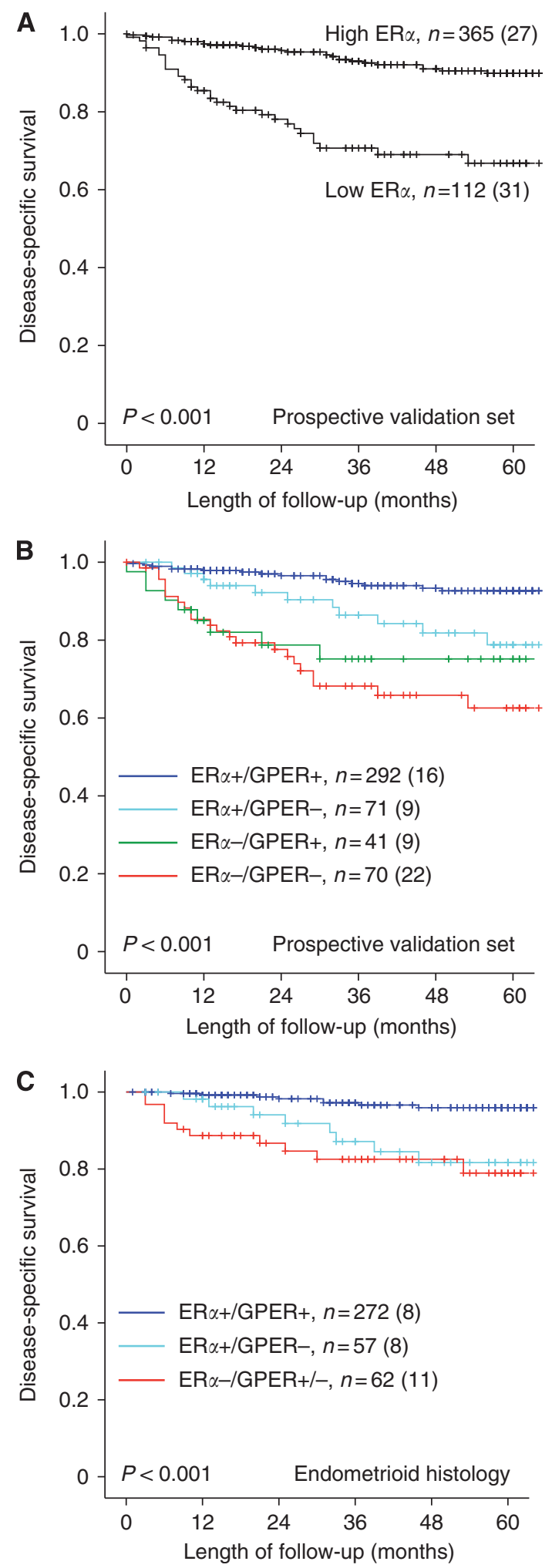

Figure 3 Disease-specific survival according to $E R \alpha$ and GPER expression. ER $\alpha$ loss $(\mathbf{A})$ is associated with poor disease-specific survival in endometrial cancer patients. When combining ER $\alpha$ and GPER staining, loss of GPER expression identifies a subgroup among ER $\alpha$-positive patients with poor survival, for all endometrial carcinomas (B) and for the subgroup of endometrioid tumours only $(\mathbf{C})$. 


\section{Loss of GPER indicates new targets for therapy amongst} $E R \alpha$-positive tumours

The gene expression profiles for $\mathrm{ER} \alpha$-positive tumours were classified in two groups based on GPER status. To investigate potential targets for treating metastatic ER $\alpha$-positive tumours with loss of GPER expression, we sought to identify new potential drugs using gene lists generated from the ER-positive tumours with and

Table 2 Loss of GPER in ER $\alpha$-positive tumours

\section{GPER}

\begin{tabular}{|c|c|c|c|}
\hline Variable & High, n (\%) & Low, $n$ (\%) & $P$-value \\
\hline Age (years) & & & 0.4 \\
\hline$<66$ & $164(82)$ & $36(18)$ & \\
\hline$\geqslant 66$ & $128(78)$ & $35(22)$ & \\
\hline FIGO-09 stage & & & 0.005 \\
\hline $1-\|$ & $268(82)$ & $57(18)$ & \\
\hline III-IV & $24(63)$ & $14(37)$ & \\
\hline Histologic type & & & 0.001 \\
\hline Endometrioid & $272(83)$ & $57(17)$ & \\
\hline Non-endometrioid & $20(59)$ & $14(4 \mid)$ & \\
\hline Histologic grade & & & 0.001 \\
\hline Grade 1/2 & $244(84)$ & $47(16)$ & \\
\hline Grade 3 & $48(67)$ & $24(33)$ & \\
\hline Metastatic nodes & & & $0.04^{\mathrm{a}}$ \\
\hline Negative & $226(82)$ & $51(18)$ & \\
\hline Positive & $13(62)$ & $8(38)$ & \\
\hline Ploidy & & & 0.02 \\
\hline Diploid & 175 (83) & $36(17)$ & \\
\hline Aneuploid & $23(66)$ & $12(34)$ & \\
\hline
\end{tabular}

Abbreviations: $E R \alpha=$ oestrogen receptor $\alpha ; G P E R=G$ protein-coupled oestrogen receptor. ${ }^{\text {a }}$ Fisher's exact test. GPER protein expression related to clinico-pathologic variables in 363 patients with $E R \alpha$-positive endometrial carcinomas.
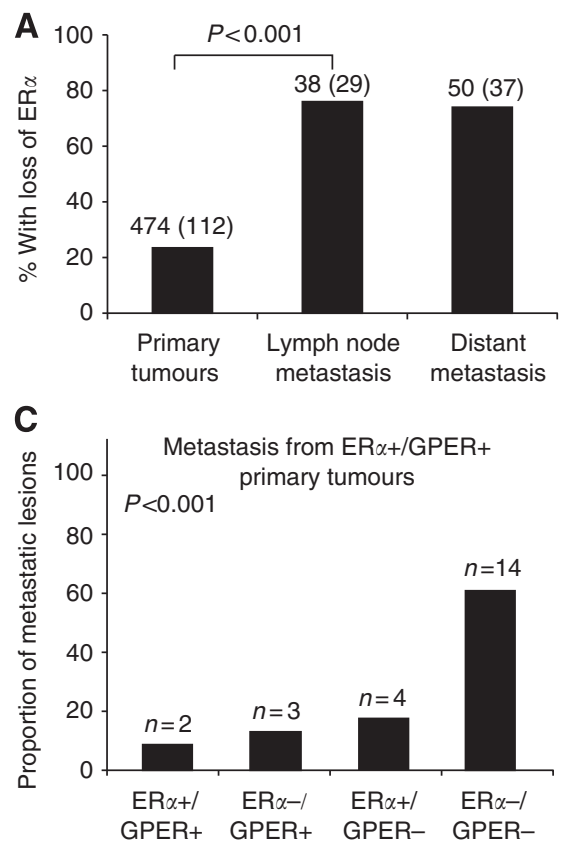

without expression of GPER. When querying a database of small molecular inhibitors (Connectivity Map) using expression data from our microarray set, two HDAC inhibitors and the PI3Kinhibitor Wortmannin were the top-ranked compounds significantly $(P<0.01)$ anti-correlated with the ER $\alpha+/$ GPER - gene signature (Table 3 ). When analysing the external data set, three HDAC inhibitors, Tricostatin A, Valpronic acid and Vorinostat, were all among the four top-ranked compounds (Supplementary Table 3). Taken together, this supports a potential for HDAC inhibitors in the treatment of metastatic $\mathrm{ER} \alpha$-positive endometrial carcinomas with loss of GPER expression.

\section{DISCUSSION}

Evaluation of hormone receptor status in endometrial cancer biopsies could potentially improve the selection of patients benefiting from endocrine therapy, as is the case in the management of breast

Table 3 Connectivity Map identifies HDAC inhibitors to be most significantly anti-correlated with the gene signature defined by GPER loss within the ER $\alpha$-positive subgroup

\begin{tabular}{lllrrl}
\hline Rank & $\begin{array}{l}\text { Name of } \\
\text { compound }\end{array}$ & Cell line & $\boldsymbol{n}^{\mathbf{a}}$ & $\boldsymbol{P}_{\text {-value }}{ }^{\mathbf{b}}$ & Known function \\
\hline 1 & Vorinostat & HL60 & 3 & $<0.001$ & HDAC inhibitor \\
2 & Wortmannin & MCF7 & 10 & $<0.001$ & PI3K-inhibitor \\
3 & Valproic acid & HL60 & 14 & 0.001 & HDAC inhibitor \\
4 & Sulfacetamide & PC3 & 2 & 0.001 & Antibiotic \\
5 & BAS-0124I6453 & MCF7 & 2 & 0.002 & \\
6 & Ciclopirox & MCF7 & 2 & 0.005 & Antifungal \\
7 & Wortmannin & PC3 & 2 & 0.006 & Pl3K-inhibitor \\
8 & Econazole & MCF7 & 2 & 0.009 & Ca ${ }^{2+}$ modulator \\
\hline
\end{tabular}

Abbreviations: $E R \alpha=$ oestrogen receptor; $G P E R=G$ protein-coupled oestrogen receptor; $\mathrm{HDAC}=$ histone deacetylase; $\mathrm{PI} 3 \mathrm{~K}=$ phosphoinositide 3-kinase. ${ }^{\text {a Number }}$ of active instances ${ }^{b} P$-value as described (Lamb et al, 2006). Compounds are ranked according to significance ( $P$-value) as anti-correlated with the gene signature from ER $\alpha$-positive subgroup with GPER loss.
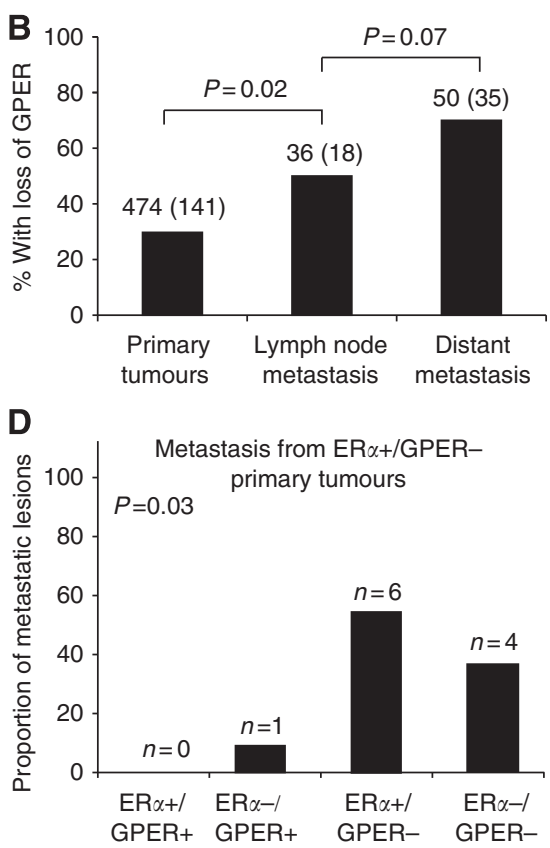

Figure 4 Loss of ER $\alpha$ and GPER in metastatic lesions. The proportion of samples with loss of ER $\alpha(\mathbf{A})$ and GPER (B) expression is lowest in primary tumours and highest in metastatic lesions. Numbers indicate total number of patients investigated, with number of patients with loss of expression in parenthesis. Distribution of ER $\alpha / G P E R$ protein expression in corresponding metastatic lesions derived from ER $\alpha+$ GPER + primary tumours $(n=23$; $\mathbf{C}$ ) and $E R \alpha+$ GPER - primary tumours $(n=I I ; \mathbf{D}) ; n=$ number of patients in each subgroup. We demonstrate a significant increase in the proportion of metastatic lesions with protein loss compared with their primary tumour counterparts (Wilcoxon signed rank test). 
cancer patients (Chen and Colditz, 2007). Only a few clinical trials in endometrial cancer are stratified according to hormone receptor status, aiming to enrich for ER $\alpha$-positive tumours (Decruze and Green, 2007). Treatment stratification based on ER $\alpha$ positivity is based on the assumption that this is the most important target for oestrogen in cancer tissue (Thomas and Gustafsson, 2011). However, although expression of $\mathrm{ER} \alpha$ predicts response to antihormonal therapy like tamoxifen in breast cancer, non-responders to tamoxifen may also express $\mathrm{ER} \alpha$, while unexpected responses are seen for patients with ER $\alpha$ loss (EBCTCG Early Breast Cancer Trialists' Collaborative Group, 2005). However, alternative receptors and targets for oestrogen might mediate unknown or even undesired effects of treatment targeting hormone receptors. We have previously investigated the expression of $\operatorname{ER} \beta$ in endometrial cancer but failed to demonstrate any significant correlation with ER $\alpha$ expression or survival (Engelsen et al, 2008). Confirming this, mRNA levels of $\operatorname{ER} \beta$ was neither correlated with phenotype nor $\mathrm{ER} \alpha$ expression in the present study. Thus, exploring expression levels of GPER in oestrogen-dependent tissue may be important to improve our prediction of response to anti-hormonal treatment. Also, GPER is emerging as a relevant drug target as both agonists (G1) (Bologa et al, 2006) and antagonists (G15, G36) (Dennis et al, $2009,2011)$ have been developed. These drugs are at present not included in the connectivity map database for testing.

In the present study of endometrial carcinomas, being the largest and most comprehensive study of GPER expression in clinically annotated samples, we find that loss of GPER protein predicts poor survival in endometrial cancer patients. We confirmed this in several independent patient series and are, to the best of our knowledge, the first group to validate this also at the mRNA level. We utilised a highly robust scoring system to define expression (Aas et al, 1996). The GPER has already been suggested as a prognostic marker in cancer, however, with strikingly different results. In breast (Filardo et al, 2006), ovarian (Smith et al, 2009) and endometrial cancers (Smith et al, 2007), high expression of GPER has previously been related to aggressive phenotypes. However, the relatively small sample size of 45 ovarian and 46 endometrial carcinomas previously studied, enrichment for high stage cases (Smith et al, 2007) and the use of different antibodies and staining cut off (median) for estimation of GPER status (Filardo et al, 2006; Smith et al, 2007, 2009) may explain the discrepancy. Additionally, none of these reports utilised quantitative assays in parallel to detect GPER. The validation of our findings, both at the mRNA level and for two different GPER antibodies and in several independent datasets, supports that the role of GPER in the endometrium should be reconsidered. When analysing ER $\alpha$ and GPER protein levels in primary tumours and their metastatic counterparts, we found significant change towards loss of both ER $\alpha$ and GPER expression in metastases, further suggesting that loss of both receptors may be important for disease progression.

Interestingly, a recent report investigated the role of GPER in breast tumourigenesis, comparing mRNA levels of GPER from tumour tissue samples with paired normal breast tissue (Poola et al, 2008). They found that GPER is downregulated in breast cancer at the mRNA level and that low GPER mRNA predicted lymph node metastasis. Like in the present study, investigation of 1250 breast cancer patients from five independent patient cohorts (Ariazi et al, 2010) reports mRNA levels for ER $\alpha$ and GPER to be correlated. Also, GPER was found to inhibit proliferation in ER $\alpha$-positive breast cancer cells in line with our findings that loss of GPER protein expression is associated with high proliferation and poor prognosis. This suggests that GPER suppresses growth in the endometrium. However, it seems puzzling that a majority of ER $\alpha$-positive cancers are enriched for expression of GPER both in our datasets and in breast cancer (Ariazi et al, 2010), indicating that intact expression of GPER reduces the aggressiveness of the disease, but is not enough to prevent tumour development. This may be explained by the dual role of GPER on the MAPK pathway (Filardo et al, 2002), where two opposing G-protein signalling pathways (PKA and EGFR) are activated by oestrogen binding to GPER. In support of this, in in vivo studies, GPER has recently been shown to regulate homoeostasis in uterine epithelia in mice by inhibiting ER $\alpha$-driven growth (Gao et al, 2011), where activation of GPER inhibits ERK1/2 and prevents $\mathrm{ER} \alpha$ phosphorylation (Ser118), rendering $\mathrm{ER} \alpha$ inactive.

The available treatment for patients with oestrogen-dependent tumours aims at targeting ER $\alpha$. As we identified a subgroup of ER $\alpha-$ positive patients with the loss of GPER expression related to aggressive disease, we explored alternative drug targets for this subgroup of patients through a search in the small molecular inhibitor database connectivity map. Three different HDAC inhibitors were among the top-ranked drugs identified as promising agents for the treatment of metastatic ER $\alpha$-positive endometrial cancers with GPER loss. In line with this, HDAC inhibitors have been associated with a transcriptional downregulation of ER $\alpha$ and its response genes (Thomas and Munster, 2009), as well as downregulation of aromatase in ER $\alpha$-positive breast cancer cells (Chen et al, 2010). In endometrial cancer cell lines, HDAC inhibitors have been reported to be anti-proliferative (Takai et al, 2004) and have been suggested to be beneficial in combination with chemotherapy in treatment of metastatic endometrial cancer (Takai and Narahara, 2010). Taken together, this suggests that the ER $\alpha /$ GPER status may be potential predictors of response to HDAC inhibitors in metastatic endometrial cancers, and needs further study.

In summary, loss of GPER predicts poor survival and is more common in metastatic lesions compared with primary lesions in $\mathrm{ER} \alpha$-positive endometrial cancers. Whether GPER in addition to $\mathrm{ER} \alpha$ status is relevant for predicting response to anti-hormonal therapy needs further studies. In addition, our data support HDAC inhibitors as promising drug candidates for treating metastatic disease, with GPER loss among ER $\alpha$-positive endometrial cancers.

\section{ACKNOWLEDGEMENTS}

We thank Britt Edvardsen, Mari Kyllesø Halle, Ingjerd Bergo, Tormund S Njølstad, Erlend S Njølstad, Gerd Lillian Hallseth, Bendik Nordanger, Beth Johannessen and Hua My Hoang for technical assistance. This study was supported by Helse Vest (911351 and 911624), the University of Bergen, the Norwegian Cancer Society (Harald Andersens grant) and the Research Council of Norway (205404 and 193373).

\section{Conflict of interest}

The authors declare no conflict of interest.

Supplementary Information accompanies the paper on British Journal of Cancer website (http://www.nature.com/bjc)

\section{REFERENCES}

Aas T, Borresen AL, Geisler S, Smith-Sorensen B, Johnsen H, Varhaug JE, Akslen LA, Lonning PE (1996) Specific P53 mutations are associated with de novo resistance to doxorubicin in breast cancer patients. Nat Med 2(7): $811-814$
Ariazi EA, Brailoiu E, Yerrum S, Shupp HA, Slifker MJ, Cunliffe HE, Black MA, Donato AL, Arterburn JB, Oprea TI, Prossnitz ER, Dun NJ, Jordan VC (2010) The G protein-coupled receptor GPR30 inhibits proliferation of estrogen receptor-positive breast cancer cells. Cancer Res 70(3): 1184-1194 
Bologa CG, Revankar CM, Young SM, Edwards BS, Arterburn JB, Kiselyov AS, Parker MA, Tkachenko SE, Savchuck NP, Sklar LA, Oprea TI, Prossnitz ER (2006) Virtual and biomolecular screening converge on a selective agonist for GPR30. Nat Chem Biol 2(4): 207-212

Carmeci C, Thompson DA, Ring HZ, Francke U, Weigel RJ (1997) Identification of a gene (GPR30) with homology to the G-proteincoupled receptor superfamily associated with estrogen receptor expression in breast cancer. Genomics 45(3): 607-617

Carter SL, Eklund AC, Kohane IS, Harris LN, Szallasi Z (2006) A signature of chromosomal instability inferred from gene expression profiles predicts clinical outcome in multiple human cancers. Nat Genet 38(9): 1043 - 1048

Chen S, Ye J, Kijima I, Evans D (2010) The HDAC inhibitor LBH589 (panobinostat) is an inhibitory modulator of aromatase gene expression. Proc Natl Acad Sci USA 107(24): 11032-11037

Chen WY, Colditz GA (2007) Risk factors and hormone-receptor status: epidemiology, risk-prediction models and treatment implications for breast cancer. Nat Clin Pract Oncol 4(7): 415-423

Decruze SB, Green JA (2007) Hormone therapy in advanced and recurrent endometrial cancer: a systematic review. Int J Gynecol Cancer 17(5): $964-978$

Dennis MK, Burai R, Ramesh C, Petrie WK, Alcon SN, Nayak TK, Bologa CG, Leitao A, Brailoiu E, Deliu E, Dun NJ, Sklar LA, Hathaway HJ, Arterburn JB, Oprea TI, Prossnitz ER (2009) In vivo effects of a GPR30 antagonist. Nat Chem Biol 5(6): $421-427$

Dennis MK, Field AS, Burai R, Ramesh C, Petrie WK, Bologa CG, Oprea TI, Yamaguchi Y, Hayashi SI, Sklar LA, Hathaway HJ, Arterburn JB, Prossnitz ER (2011) Identification of a GPER/GPR30 antagonist with improved estrogen receptor counterselectivity. J Steroid Biochem Mol Biol 127: $358-366$

EBCTCG Early Breast Cancer Trialists' Collaborative Group (2005) Effects of chemotherapy and hormonal therapy for early breast cancer on recurrence and 15-year survival: an overview of the randomised trials. Lancet 365(9472): $1687-1717$

Engelsen IB, Stefansson IM, Akslen LA, Salvesen HB (2008) GATA3 expression in estrogen receptor alpha-negative endometrial carcinomas identifies aggressive tumors with high proliferation and poor patient survival. Am J Obstet Gynecol 199(5): 543.e1-e7

Filardo EJ, Graeber CT, Quinn JA, Resnick MB, Giri D, DeLellis RA, Steinhoff MM, Sabo E (2006) Distribution of GPR30, a seven membranespanning estrogen receptor, in primary breast cancer and its association with clinicopathologic determinants of tumor progression. Clin Cancer Res 12(21): 6359-6366

Filardo EJ, Quinn JA, Bland KI, Frackelton Jr AR (2000) Estrogen-induced activation of Erk-1 and Erk-2 requires the $G$ protein-coupled receptor homolog, GPR30, and occurs via trans-activation of the epidermal growth factor receptor through release of HB-EGF. Mol Endocrinol 14(10): $1649-1660$

Filardo EJ, Quinn JA, Frackelton Jr AR, Bland KI (2002) Estrogen action via the G protein-coupled receptor, GPR30: stimulation of adenylyl cyclase and cAMP-mediated attenuation of the epidermal growth factor receptor-to-MAPK signaling axis. Mol Endocrinol 16(1): 70-84

Gao F, Ma X, Ostmann AB, Das SK (2011) GPR30 activation opposes estrogen-dependent uterine growth via inhibition of stromal ERK1/2 and estrogen receptor alpha (ERalpha) phosphorylation signals. Endocrinology 152(4): $1434-1447$

Lamb J, Crawford ED, Peck D, Modell JW, Blat IC, Wrobel MJ, Lerner J, Brunet JP, Subramanian A, Ross KN, Reich M, Hieronymus H, Wei G, Armstrong SA, Haggarty SJ, Clemons PA, Wei R, Carr SA, Lander ES, Golub TR (2006) The Connectivity Map: using gene-expression signatures to connect small molecules, genes, and disease. Science 313(5795): $1929-1935$

Livak KJ, Schmittgen TD (2001) Analysis of relative gene expression data using real-time quantitative PCR and the 2-[Delta][Delta]CT method. Methods 25(4): 402-408

Maggiolini M, Picard D (2010) The unfolding stories of GPR30, a new membrane-bound estrogen receptor. J Endocrinol 204(2): 105-114

Poola I, Abraham J, Liu A, Marshalleck JJ, Dewitty RL (2008) The cell surface estrogen receptor, G protein-coupled receptor 30 (GPR30), is markedly down regulated during breast tumorigenesis. Breast Cancer 1: $65-78$

Prossnitz ER, Barton M (2011) The G-protein-coupled estrogen receptor GPER in health and disease. Nat Rev Endocrinol 7(12): 715-726

Salvesen HB, Carter SL, Mannelqvist M, Dutt A, Getz G, Stefansson IM, Raeder MB, Sos ML, Engelsen IB, Trovik J, Wik E, Greulich H, Bo TH, Jonassen I, Thomas RK, Zander T, Garraway LA, Oyan AM, Sellers WR, Kalland KH, Meyerson M, Akslen LA, Beroukhim R (2009) Integrated genomic profiling of endometrial carcinoma associates aggressive tumors with indicators of PI3 kinase activation. Proc Natl Acad Sci USA 106(12): 4834-4839

Salvesen HB, Das S, Akslen LA (2000) Loss of nuclear p16 protein expression is not associated with promoter methylation but defines a subgroup of aggressive endometrial carcinomas with poor prognosis. Clin Cancer Res 6(1): 153-159

Salvesen HB, Iversen OE, Akslen LA (1999) Prognostic significance of angiogenesis and $\mathrm{Ki}-67, \mathrm{p} 53$, and p21 expression: a population-based endometrial carcinoma study. J Clin Oncol 17(5): 1382-1390

Singh M, Zaino RJ, Filiaci VJ, Leslie KK (2007) Relationship of estrogen and progesterone receptors to clinical outcome in metastatic endometrial carcinoma: a Gynecologic Oncology Group Study. Gynecol Oncol 106(2): $325-333$

Smith HO, Arias-Pulido H, Kuo DY, Howard T, Qualls CR, Lee SJ, Verschraegen CF, Hathaway HJ, Joste NE, Prossnitz ER (2009) GPR30 predicts poor survival for ovarian cancer. Gynecol Oncol 114(3): $465-471$

Smith HO, Leslie KK, Singh M, Qualls CR, Revankar CM, Joste NE, Prossnitz ER (2007) GPR30: a novel indicator of poor survival for endometrial carcinoma. Am J Obstet Gynecol 196(4): 386.e1-9; discussion 386.e9-e11

Stefansson IM, Salvesen HB, Akslen LA (2004) Prognostic impact of alterations in $\mathrm{P}$-cadherin expression and related cell adhesion markers in endometrial cancer. J Clin Oncol 22(7): $1242-1252$

Takai N, Desmond JC, Kumagai T, Gui D, Said JW, Whittaker S, Miyakawa I, Koeffler HP (2004) Histone deacetylase inhibitors have a profound antigrowth activity in endometrial cancer cells. Clin Cancer Res 10(3): $1141-1149$

Takai N, Narahara H (2010) Preclinical studies of chemotherapy using histone deacetylase inhibitors in endometrial cancer. Obstet Gynecol Int 2010: 923824

Thomas C, Gustafsson JA (2011) The different roles of ER subtypes in cancer biology and therapy. Nat Rev Cancer 11(8): 597-608

Thomas P, Pang Y, Filardo EJ, Dong J (2005) Identity of an estrogen membrane receptor coupled to a $\mathrm{G}$ protein in human breast cancer cells. Endocrinology 146(2): 624-632

Thomas S, Munster PN (2009) Histone deacetylase inhibitor induced modulation of anti-estrogen therapy. Cancer Lett 280(2): 184-191

Trovik J, Wik E, Stefansson IM, Marcickiewicz J, Tingulstad S, Staff AC, Njolstad TS, Vandenput I, Amant F, Akslen LA, Salvesen H (2011) Stathmin overexpression identifies high risk patients and lymph node metastasis in endometrial cancer. Clin Cancer Res 17(10): 3368-3377

This work is published under the standard license to publish agreement. After 12 months the work will become freely available and the license terms will switch to a Creative Commons Attribution-NonCommercial-Share Alike 3.0 Unported License. 